\title{
BMJ Global Health Psychosocial wellbeing of patients with multidrug resistant tuberculosis voluntarily confined to long-term hospitalisation in Nigeria
}

Olanrewaju Oladimeji, ${ }^{1,2}$ Boniface Ayanbekongshie Ushie, ${ }^{3}$

Ekerette Emmanuel Udoh, ${ }^{3}$ Kelechi Elizabeth Oladimeji, ${ }^{2,4}$ Olusoji Mayowa Ige, ${ }^{5}$ Olusegun Obasanya, ${ }^{6}$ Daisy Lekharu, ${ }^{7}$ Olayinka Atilola, ${ }^{8}$ Lovett Lawson, ${ }^{9}$ Osman Eltayeb, ${ }^{10}$ Mustapha Gidado, ${ }^{11}$ Joyce M Tsoka-Gwegweni, ${ }^{2}$ Chikwe A Ihekweazu, ${ }^{6}$ Charles S Chasela ${ }^{1}$

To cite: Oladimeji 0 , Ushie BA, Udoh E E, et al. Psychosocial wellbeing of patients with multidrug resistant tuberculosis voluntarily confined to longterm hospitalisation in Nigeria. BMJ Global Health 2016;1:e000006. doi:10.1136/bmjgh-2015000006

Received 4 November 2015 Revised 9 August 2016 Accepted 13 August 2016

CrossMark

For numbered affiliations see end of article.

Correspondence to Dr Olanrewaju Oladimeji; droladfb@gmail.com

\section{ABSTRACT}

Background and objective: Patient isolation, which is a widely successful treatment strategy for tuberculosis (TB), has been suspected to have effects on patient psychosocial wellbeing. We assessed the psychosocial wellbeing of multidrug resistant TB (MDR-TB) patients in voluntary and isolated longterm hospitalisation in Nigeria.

Methods: 98 accessible and consenting patients in four drug-resistant treatment centres (University College Hospital and Government Chest Hospital, Ibadan; Mainland Hospital, Lagos, and Lawrence Henshaw Memorial Hospital, Calabar) were enrolled in this study. Data were collected using an 18-item psychosocial wellbeing questionnaire including sociodemographic characteristics. We used descriptive statistics to present demographic characteristics; the $\chi^{2}$ test was used to assess associations between psychosocial wellbeing and independent variables and the relationship was modelled using logistic regression.

Results: The mean age of respondents was $36.1 \pm$ 11.9 years and $63 \%$ were males. Respondents had been in hospital an average of $4.5 \pm 1.9$ months. Females had more psychosocial concerns compared with males. The most common concerns recorded among respondents were concern that people will get to know that the respondent had a bad type of TB $(70 \%)$, discontent with being separated from and longing for the company of their marital partner $(72 \%)$, concerns that they may have taken too many drugs $(73 \%)$, and displeasure with being unable to continue to engage in their usual social and economic activities (75\%). Respondents who were employed had eight times the odds of having more psychosocial concerns than the median number among respondents. Respondents who were supported by their own families during hospitalisation experienced a lower burden of psychosocial concerns compared with those who were supported by third parties.

\section{Key questions}

What is already known about this topic?

- The estimated number of patients with multidrug resistant tuberculosis (MDR-TB) in Nigeria is between 2700 and 4500 .

- The prevalence rate of MDR-TB was 2.9\% among new patients and $14.5 \%$ among previously treated cases in Nigeria.

- Hospitalisation, which is often long-term, is the adopted strategy for the management of MDR-TB in Nigeria, but the psychosocial burden this places on patients is yet to be assessed

What are the new findings?

- Isolation as one of the strategies to treat MDR-TB has produced successful outcomes but this approach has implications for psychosocial wellbeing of patients.

- Patients on hospital admission for MDR-TB have a lot of psychosocial concerns, including discontent about being separated from and longing for the company of their marital partner and displeasure with being unable to continue to engage in their usual social and economic activities.

Recommendations for policy

- There is a need for a paradigm shift in the management of MDR-TB such that fewer patients are hospitalised in favour of community-based outpatient treatment, with measures put in place to ensure adherence.

Conclusions: Prolonged hospitalisation resulted in significant psychosocial burden for the MDR-TB patients in our study centres. There is a need to consider alternative approaches that place less psychosocial burden on patients without compromising quality of care. 


\section{INTRODUCTION}

Tuberculosis (TB) is a communicable disease caused by Mycobacterium tuberculosis, an organism that is most commonly transmitted by inhaling airborne droplets expelled by the cough of a person with infectious TB. ${ }^{12}$ $\mathrm{TB}$ has remained a major public health problem in spite of the availability of effective treatment. ${ }^{34}$ Although significant progress has made in the eradication of the disease, the emergence of co-morbid HIV as well as multiple drug resistance to $\mathrm{TB}^{5}$ has led to a resurgence of the disease. ${ }^{6}$ Multidrug resistant TB (MDR-TB) is a form of drug resistant TB in which the TB bacteria becomes resistant to at least isoniazid (INH) and rifampin (RIF), which are among the drugs commonly used to treat TB. MDR-TB is more difficult to treat, and often requires up to 2 years of multidrug treatment, ${ }^{2}$ sometimes as an inpatient.

Nigeria is one of the major reservoirs of TB worldwide with an estimated incidence of 311 cases per 100000 population and a mortality rate of 81 per 100000 population. ${ }^{7}$ Furthermore, the prevalence rate of $\mathrm{TB}$ in Nigeria stood at 521 per 100000 population in $2007 .^{8}$ MDR-TB is also very common in Nigeria, with a prevalence rate of $2.9 \%$ reported among newly detected cases in 2012, and a prevalence rate of $14.5 \%$ among previously treated cases. The number of patients with MDR-TB in Nigeria has been estimated to be between 2700 and $4500 .^{9} 10$

Efforts at prevention and control of $\mathrm{TB}$ as a matter of necessity have been targeted at providing free directly observed therapy (DOT) to sputum-positive patients. However, adherence to treatment has remained a major challenge, which creates the problem of drug resistance. Drug resistant TB compounds the risk posed to public health, because without successful completion of treatment and achievement of cure, a patient with TB can become a source that transmits the infection with a more virulent strain to others. ${ }^{11}$ The DOT strategy has been used as an effective means to address adherence problems. The development of effective treatment strategies such as DOT has shifted the focus of TB management from the prevention of mortality to the avoidance of morbidity. ${ }^{12}$ If TB controls are not strengthened, the WHO estimates that, by 2020, 70 million more people will die from the disease. Therefore, individuals who have TB must be effectively treated to prevent them from infecting others since the disease is airborne and very contagious. The rationale that informs the DOT strategy and quarantine, or treatment in confinement, is doubt about the effectiveness of ambulatory treatment to guarantee treatment adherence. ${ }^{13}$ Besides, there is the possibility that the disease will spread to the household and the community at large, and potentially increase the risk of development of drug-resistant strains if patients are allowed to undertake self-treatment.

Although it raises ethical and human rights concerns, one of the strategies for treating MDR-TB includes optional involuntary/voluntary hospital treatment depending on the severity of the patient's condition and available programme resources. This modality was premised on the public safety concerns of untreated or poorly treated MDR-TB. Recently, through the support of the Damien Foundation Belgium, an 8-month period of intensive treatment through isolated hospitalisation of patients with MDR-TB was initiated as a strategy for dealing with the rising cases of MDR-TB in Nigeria. Within this programme, patients, after being diagnosed with MDR-TB, are placed on long-term confined hospitalisation. People in the programme are provided incentives in the form of a monthly stipend and/or other forms of needs as motivation and support. Treatment and standard hospital accommodation and resources are provided completely free. Family visits to the hospitalised subjects are highly restricted.

However, in as much as there are incentives and efforts to reduce the psychosocial burden of the confinement and hospitalisation, it is most likely that such patients still have major psychosocial concerns. As with any other chronic medical condition, hospitalised patients with MDR-TB have to adjust their aspirations, lifestyle, family life, employment, and other psychosocial and environmental realities within their confinement. They may also have to deal with other issues such as adjustment to their role as a patient, financial worries, family issues, coping, accessing available support services, disruptions to usual routine, and the emotional reactions to the chronic disease itself. These psychosocial outcomes are very important in the treatment process and have implications for the outcomes of hospitalisation in patients with a chronic condition. ${ }^{14-16}$ Beyond intuitive responses, the psychosocial concern of patients with MDR-TB in Nigeria is not well studied. For a vulnerable group in a competitive environment where resources are scarce, if the psychosocial wellbeing of patients with MDR-TB is not well documented, the chances of effectively meeting their psychosocial needs may be severely constrained. More importantly, documenting the nature and extent of the psychosocial burden of long-term hospitalisation will stimulate further discourse on alternative management strategies. The objective of this study is therefore to assess the psychosocial wellbeing of patients with MDR-TB who are confined in treatment facilities across Nigeria.

\section{METHODS \\ Setting}

The four MDR-TB treatment centres in Nigeria involved in the study, and the number of patients enrolled in the study in each centre, were: University College Hospital Ibadan (24 patients), Government Chest Hospital, Jericho, Ibadan (22 patients), Dr Lawrence Henshaw Memorial Hospital, Calabar (12 patients), and Mainland General Hospital, Lagos (40 patients). Admission of patients with MDR-TB into the treatment programme started in January 2012, and recruitment into the study 
was undertaken in October of the same year. All available and consenting patients were included in the study. These patients were admitted to the hospitals on the basis of having developed resistance to first line anti-TB drugs. One of the conditions for admission was a willingness of the patients to stay hospitalised until they were fit for discharge. Fitness for discharge was defined as two consecutive negative sputum results, and a satisfactory general medical condition. ${ }^{17}$ The potential patients were also informed that the estimated duration of admission was expected to be about 6-8 months, based on global estimates. ${ }^{18}$ The present study is part of a larger interdisciplinary study evaluating the presentation, management, management constraints, and outcome of patients on inpatient care for MDR-TB in Nigeria.

\section{Measures}

We used a self-administered questionnaire containing 18 items related to psychosocial wellbeing (table 2). The questionnaire was developed in stages. The first stage collated the psychosocial concerns which previous MDR-TB patients in our facilities had expressed in the course of pre-admission counselling and during the regular ward rounds in the hospitals. This was obtained from the resident health workers (such as nurses and social workers) in our facilities as well as from ward-round notes. Further information about the psychosocial concerns of patients with $\mathrm{TB}$ were obtained from first-person accounts which had been recorded in the literature. ${ }^{19}$ The information obtained from these sources were converted into 'active-voice' questions (example: "Ever since you were admitted into this hospital, have you been concerned that people will say bad things of you?"). A total of 22 questions were thus generated initially. A pilot testing for internal consistency was then conducted by administering the initial questionnaire to a few respondents. Four items were eliminated because their scores suggested that they measured the same construct with other items on the scale. The final questionnaire had 18 items with a Cronbach's $\alpha$ of 0.902. We were also able to identify four different domains of psychosocial concerns on the questionnaire which included social disconnection, separation from family, fear of hospital environment, and loss of social responsibility. The questionnaire was administered to respondents in a face-to-face interview. Each question was put to the patient and it was ascertained whether the patient understood the questions. The response to the question was recorded as 'Yes' if the respondent responded in the affirmative and agreed that he/she had been bothered by the concern more than once since admission to the facility. Otherwise, the response was recorded as 'No'. Other information obtained included sociodemographic characteristics and medical history. The questionnaires were administered by trained collaborators within each of the hospitals.

\section{Statistical analysis}

The statistical package IBM SPSS V.20 was used for all analysis. Descriptive statistics were used in analysing all variables at the univariate level while the $\chi^{2}$ test was used to examine the association between psychosocial wellbeing, mental health, demographic variables (such as location of treatment, current status of employment, sex, age, education, and marital status) and clinical variables (such as number of TB treatments in the past, number of years on TB treatment, and current duration on TB treatment admission). Multiple logistic regression was used to determine the factors that were independently associated with psychosocial wellbeing.

\section{Ethical consideration}

Ethical approval was given by the Oyo state, Ministry of Health Ethics Committee in January 2012. Participant information was anonymised and de-identified before analysis. Informed consent was obtained from the participants. The named ethics committees approved the consent procedure in addition to the study protocol.

\section{RESULTS}

All of the 98 inpatients admitted to our treatment facilities were enrolled in the study, and all agreed to participate. Table 1 summarises the respondents' sociodemographic characteristics. The mean $\pm \mathrm{SD}$ age of the patients was $36.1 \pm 11.9$ years, and $63.3 \%$ were males. Patients had spent an average of $4.5 \pm 1.9$ months in the hospital at the time of the study. At the time of admission into the TB treatment programme, the majority $(74.5 \%)$ were unemployed. More than half $(54 \%)$ of respondents had received $\mathrm{TB}$ treatment earlier. Other important sociodemographic characteristics of the study respondents are also shown in table 1 .

In regard to the psychosocial concerns of the respondents, the most common concern (approximately 70\%) on the social disconnection scale was that people would find out that the respondent had a bad type of TB (table 2). Being separated from and longing for the company of the marital partner was the most common $(72 \%)$ concern on the family sub-scale. Concern that they may have taken too many drugs was the most common $(73 \%)$ on the fear of hospital/drugs sub-scale, while being unable to continue to engage in their usual social and economic activities was the most common (75\%) concern on the loss of social responsibility subscale. Other concerns are also shown in table 2. A graphical representation of the different psychosocial concerns is shown in figure 1.

\section{Factors independently associated with psychosocial wellbeing}

Based on a median score of 10 (every 'Yes' response in the 18-item questionnaire was taken as a score of 1), the respondents were dichotomised into two groups, namely 'good' or 'poor' psychosocial wellbeing. A score of $\geq 10$ 
Table 1 Sociodemographic characteristics of respondents

\begin{tabular}{lcc}
\hline Characteristics & Frequency & Percentage \\
\hline Sex & & \\
$\quad$ Male & 62 & 63.3 \\
Female & 36 & 36.7 \\
Age (mean \pm SD & $36.1 \pm 11.97$ years) & \\
$\quad \leq 30$ years & 34 & 39.5 \\
$>30$ years & 52 & 60.5 \\
Marital status & & \\
$\quad$ Currently single & 44 & 44.9 \\
$\quad$ Currently married & 54 & 55.1
\end{tabular}

Religion

\begin{tabular}{lcc} 
Christianity & 64 & 65.3 \\
\hline Islam & 34 & 34.7 \\
Education & & \\
\hline No formal & 13 & 14.5 \\
Primary & 25 & 27.8 \\
\hline Secondary & 39 & 43.3 \\
\hline Post-secondary & 13 & 14.4 \\
Current employment status & \\
\hline Unemployed & 70 & 74.5 \\
\hline Employed & 24 & 25.5 \\
\hline Children & & \\
\hline Yes & 64 & 65.3 \\
\hline No & 34 & 34.7 \\
Children in school & & \\
\hline Yes & 57 & 82.6 \\
\hline No & 12 & 17.4 \\
\hline Person providing for children & \\
\hline Myself & 34 & 12.0 \\
\hline My spouse & 12 & 17.9 \\
\hline My family & 13 & 19.4 \\
\hline Other & 8 & \\
\hline
\end{tabular}

Family members visit

$\begin{array}{lll}\text { Yes } & 72 & 80.0 \\ \text { No } & 18 & 20.0\end{array}$

Number of TB treatments in the past

$\begin{array}{lll}1 & 16 & 16.3 \\ 2 & 29 & 29.6 \\ 3 & 36 & 36.7 \\ \geq 4 & 17 & 17.3\end{array}$

Number of years on TB treatment

\begin{tabular}{lll}
$1-2$ & 21 & 21.4 \\
$3-4$ & 27 & 27.6 \\
$5-10$ & 34 & 34.7 \\
$>10$ & 16 & 16.3 \\
\hline
\end{tabular}

Table 1 Continued

\begin{tabular}{ccc}
\hline Characteristics & Frequency & Percentage \\
\hline Current duration of admission (months) & \\
1 & 4 & 4.1 \\
2 & 16 & 16.3 \\
3 & 9 & 9.2 \\
\hline 4 & 10 & 10.2 \\
5 & 35 & 35.7 \\
6 & 1 & 1.0 \\
7 & 16 & 16.3 \\
8 & 7 & 7.1 \\
\hline
\end{tabular}

TB, tuberculosis.

Table 2 Distribution of respondents by psychosocial wellbeing items

\begin{tabular}{|c|c|c|}
\hline Domains & No & Yes \\
\hline \multicolumn{3}{|l|}{ Social disconnection } \\
\hline $\begin{array}{l}\text { Concerned that people will say bad } \\
\text { things of me }\end{array}$ & $32(32.7)$ & $66(67.3)$ \\
\hline $\begin{array}{l}\text { Fear of social rejection/isolation } \\
\text { due to stigma }\end{array}$ & $38(38.8)$ & $60(61.2)$ \\
\hline $\begin{array}{l}\text { Worried that people will know I am } \\
\text { being treated for TB in the hospital }\end{array}$ & $47(48.0)$ & $51(52.0)$ \\
\hline Loneliness & $30(30.6)$ & $68(69.4)$ \\
\hline \multicolumn{3}{|l|}{ Separation from family } \\
\hline Worried about my family & $29(29.6)$ & $69(70.4)$ \\
\hline Miss being with my partner & $27(27.6)$ & $71(72.4)$ \\
\hline $\begin{array}{l}\text { Long hospital stay denies me } \\
\text { support from my family }\end{array}$ & $38(38.8)$ & $60(61.2)$ \\
\hline Being separated from my family & $27(27.6)$ & $71(72.4)$ \\
\hline $\begin{array}{l}\text { Worried about disengagement from } \\
\text { community }\end{array}$ & $41(41.8)$ & $57(58.2)$ \\
\hline \multicolumn{3}{|l|}{ Fear of hospitals and drugs } \\
\hline Hospital feels like a prison & $39(39.8)$ & $59(60.2)$ \\
\hline $\begin{array}{l}\text { Concern about side-effects of } \\
\text { medicines }\end{array}$ & $32(32.7)$ & $66(67.3)$ \\
\hline $\begin{array}{l}\text { Concern that I have taken too many } \\
\text { drugs }\end{array}$ & $26(26.5)$ & $72(73.5)$ \\
\hline Have ability to tolerate side-effects & $43(43.9)$ & $55(56.1)$ \\
\hline Low expectations of cure & $51(52.0)$ & $47(48.0)$ \\
\hline \multicolumn{3}{|l|}{ Loss of social responsibility } \\
\hline $\begin{array}{l}\text { Miss doing all the usual things I } \\
\text { used to do }\end{array}$ & $23(23.5)$ & $75(75.5)$ \\
\hline Worried that I will lose my job & $48(49.0)$ & $50(51.0)$ \\
\hline $\begin{array}{l}\text { Frustrations about the temporary } \\
\text { inability to work/study/perform } \\
\text { social responsibilities }\end{array}$ & $52(53.1)$ & $46(46.9)$ \\
\hline Worried about income & $33(33.7)$ & $65(66.3)$ \\
\hline
\end{tabular}


Figure 1 Percentage distribution of patients according to psychosocial wellbeing items.

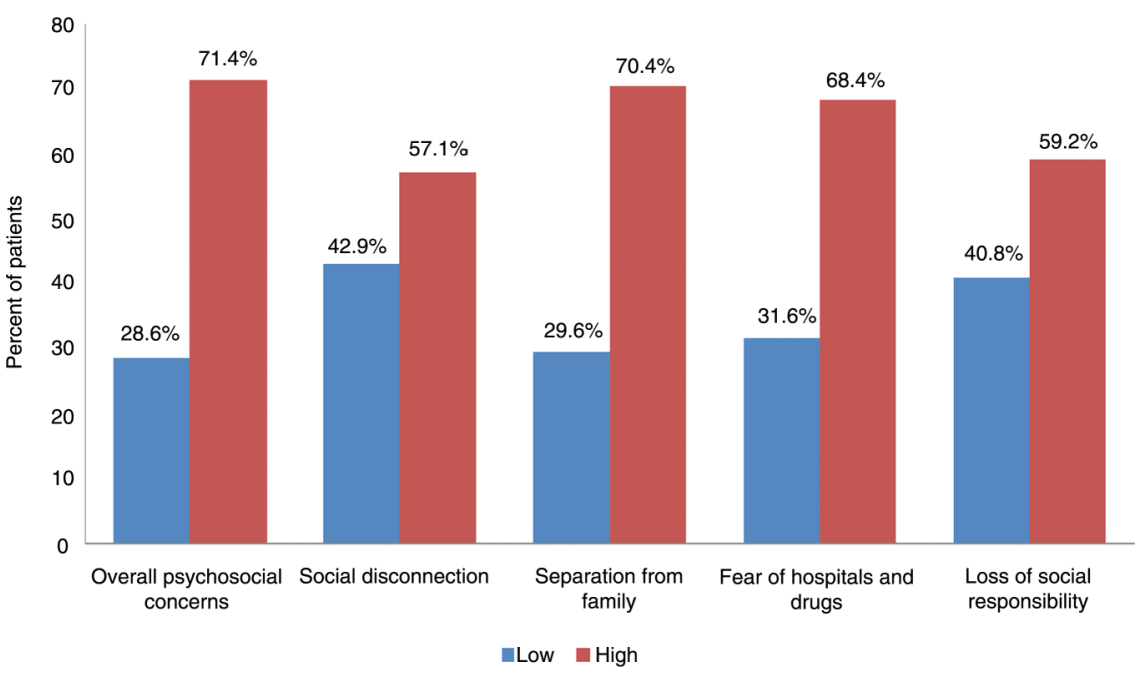

was taken as indicative of poor psychosocial wellbeing, while those with a score $<10$ was taken as good psychosocial wellbeing. Table 3 shows the sociodemographic and clinical variables that were associated with poorer psychosocial wellbeing in univariate analysis. All variables that were significantly associated were tested in a logistic regression model. Variables that were predictive of overall poorer psychosocial wellbeing were employment status, number of years on TB treatment, and current duration of admission (table 4). As shown in table 4, respondents who were employed were eight times more likely to experience poor psychosocial wellbeing compared with those who were unemployed (OR 8.3, 95\% CI 1.31 to 14.2 ). Patients who had spent a longer time on admission had a higher likelihood of experiencing poor psychosocial wellbeing; for example, those who had spent 7-8 months were three times more likely to have poor psychosocial wellbeing compared to those who had only spent $\leq 2$ months (OR 3.12, 95\% CI 1.19 to 19.34.). When children's needs were being provided for by other members or relations of patients besides their spouses, the likelihood of a subject having poor psychosocial wellbeing, with respect to social disconnection, was very high relative to when it was provided by the respondents themselves. Analysis for the subdomains of psychosocial wellbeing was also done to see how the predictors operate on the separate domain (table 5). Educational status was significant in the adjusted logistic model in predicting high social disconnection; those in the post-secondary category showed a much higher likelihood of having psychosocial concern with respect to social disconnection. Respondents who were employed were also more likely to exhibit a higher likelihood of social disconnection compared with those who were unemployed. The odds of social disconnection were higher with increasing length of stay in hospital (table 5). Concern about separation from family was predicted by current employment status, number of years on TB treatment, and current duration of admission. For example, those who had been on TB treatment for about 5-10 years were more likely to feel more separated from their family (OR 7.76, 95\% CI 2.20 to 15.14) than those who had been on treatment for about 1-2 years. Fear of hospitals and drugs were predicted by employment status, number of years on TB treatment, and current duration of admission. Females were less likely to show poor psychosocial wellbeing with respect to loss of social responsibility compared with males (OR 0.08 , $95 \%$ CI 0.08 to 1.19). Current duration of admission also remained a predictor of a high feeling of loss of social responsibility.

\section{DISCUSSION}

The results of this study show that patients with MDR-TB who are on long-term hospitalisation in our study centres have a lot of psychosocial concerns in regard to the nature of their illness as well as the prolonged hospitalisation. The degree of these concerns vary, but our study shows that those who were employed before hospitalisation and those whose duration of admission was longer had higher odds of having a lot more psychosocial concerns. These results, even though they represent new data-based information in the field, are not at all surprising. This is because the combined psychosocial impact of a chronic debilitating illness such as MDR-TB on the one hand, and prolonged isolation and hospitalisation on the other, will certainly be fraught with a lot of psychosocial concerns. Patients enrolled in a treatment programme like ours are not only removed from their families and communities, but are isolated from the social day-to-day lives and routines that they are used to, and are put in formalised and isolated institutions/ hospitals for treatment. People suffering from chronic health conditions such as TB are known to experience a sense of social isolation and stigma. ${ }^{20-22}$ Likewise, concerns about the side-effects of drugs, the fear of isolation from family and friends while in hospital, and loss of income are all well documented concerns with patients diagnosed with even less problematic forms of TB. ${ }^{12} 23-27$ 
Table 3 Association between overall psychosocial wellbeing and sociodemographic/medical history

\begin{tabular}{lllll}
\hline & \multicolumn{4}{l}{ Overall psychosocial wellbeing } \\
\cline { 2 - 5 } Characteristics & Good & Poor & $\chi^{2}$ & p Value \\
\hline Sex & & & & \\
$\quad$ Male & 30.6 & 69.4 & 0.356 & 0.551 \\
$\quad$ Female & 25.0 & 75.0 & & \\
\hline Age & & & & \\
$\quad \leq 30$ years & 44.1 & 55.9 & 6.175 & 0.013 \\
$\quad>30$ years & 19.2 & 80.8 & & \\
\hline $\begin{array}{l}\text { Marital status } \\
\quad \text { Currently single }\end{array}$ & 36.4 & 63.6 & 2.376 & 0.123 \\
$\quad$ Currently married & 22.2 & 77.8 & & \\
\hline
\end{tabular}

Religion

\begin{tabular}{|rrrrr|}
\hline Christianity & 29.7 & 70.3 & 0.113 & 0.737 \\
\hline Islam & 26.5 & 73.5 & & \\
\hline Education & & & & \\
\hline No formal & 0.0 & 100.0 & $8.426^{\star}$ & 0.077 \\
\hline Primary & 44.0 & 56.0 & & \\
\hline Secondary & 28.2 & 71.8 & & \\
\hline Post-secondary & 23.1 & 76.9 & & \\
\hline
\end{tabular}

Current employment status

\begin{tabular}{|c|c|c|c|c|}
\hline Unemployed & 34.3 & 65.7 & 6.016 & 0.014 \\
\hline Employed & 8.3 & 91.7 & & \\
\hline \multicolumn{5}{|l|}{ Children } \\
\hline Yes & 38.2 & 61.8 & 2.382 & 0.123 \\
\hline No & 23.4 & 76.6 & & \\
\hline \multicolumn{5}{|c|}{ Children in school } \\
\hline Yes & 16.7 & 83.3 & 0.220 & 0.639 \\
\hline No & 22.8 & 77.2 & & \\
\hline \multicolumn{5}{|c|}{ Person providing for children } \\
\hline Myself & 20.6 & 79.4 & $3.198^{\star}$ & 0.362 \\
\hline My spouse & 25.0 & 75.0 & & \\
\hline My family & 23.1 & 76.9 & & \\
\hline Other & 38.5 & 61.5 & & \\
\hline \multicolumn{5}{|c|}{ Family members visit } \\
\hline Yes & 30.6 & 69.4 & 0.053 & 0.818 \\
\hline No & 27.8 & 72.2 & & \\
\hline \multicolumn{5}{|c|}{ Number of TB treatments in the past } \\
\hline 1 & 43.8 & 56.2 & $4.242^{*}$ & 0.236 \\
\hline 2 & 27.6 & 72.4 & & \\
\hline 3 & 30.6 & 69.4 & & \\
\hline$\geq 4$ & 11.8 & 88.2 & & \\
\hline \multicolumn{5}{|c|}{ Number of years on TB treatment } \\
\hline $1-2$ & 42.9 & 57.1 & $8.865^{\star}$ & 0.031 \\
\hline $3-4$ & 40.7 & 59.3 & & \\
\hline $5-10$ & 11.8 & 88.2 & & \\
\hline$>10$ & 25.0 & 75.0 & & \\
\hline
\end{tabular}

Continued
Table 3 Continued

\begin{tabular}{lcccc}
\hline & \multicolumn{4}{c}{ Overall psychosocial wellbeing } \\
\cline { 2 - 5 } Characteristics & Good & Poor & $\chi^{2}$ & p Value \\
\hline Current duration of admission & & & \\
1-2 & 55.0 & 45.0 & $9.117^{\star}$ & 0.028 \\
3-4 & 15.8 & 84.2 & & \\
5-6 & 25.0 & 75.0 & & \\
7-8 & 21.7 & 78.3 & & \\
Treatment centre & & & & \\
UCH, Ibadan & 12.5 & 87.5 & $4.789^{*}$ & 0.188 \\
GCH, Ibadan & 31.8 & 68.2 & & \\
DLHMH, Calabar & 25.0 & 75.0 & \\
MGH, Lagos & 37.5 & 62.5 & \\
\hline
\end{tabular}

*Likelihood ratio.

DLHMH, Dr Lawrence Henshaw Memorial Hospital, GCH,

Government Chest Hospital; MGH, Mainland General Hospital; TB, tuberculosis; UCH, University College Hospital.

Table 4 Regression model predicting poor psychosocial wellbeing of patients

\section{Overall psychosocial wellbeing}

Selected predictors Adjusted OR (95\% Cl)

Current employment status

$\begin{array}{ll}\text { Unemployed } & 1.00 \\ \text { Employed } & 8.3^{\star *}(1.31 \text { to } 14.2)\end{array}$

Number of years on TB treatment

$\begin{array}{ll}1-2 & 1.00 \\ 3-4 & 3.59(0.40 \text { to } 31.98) \\ 5-10 & 7.19^{* *}(1.96 \text { to } 13.32) \\ >10 & 2.91(0.28 \text { to } 29.4)\end{array}$

Current duration of admission

$\begin{array}{ll}1-2 & 1.00 \\ 3-4 & 7.88^{\star *}(2.42 \text { to } 15.7) \\ 5-6 & 2.92(0.47 \text { to } 6.17) \\ 7-8 & 3.12^{\star *}(1.19 \text { to } 7.34)\end{array}$

Variables included in logit model were sex, age, marital status, religion, education, current employment status, children, children in school, person providing for children, number of TB treatments in past, number of years on TB treatment, and current duration of admission.

** Significant at $p<0.05$.

a. Model $\chi^{2}=21.527, p=0.001$, Negelkerk $R^{2}=0.427$.

b. Model $\chi^{2}=24.806, p=0.006$, Negelkerk $R^{2}=0.433$.

TB, tuberculosis.

Although the $\mathrm{WHO}^{18}$ recognises inpatient care at a district hospital as one of the management models for MDR-TB, there had been earlier concerns about the propriety of this approach. These concerns include an earlier observation that hospitalisation of persons with MDR-TB is more costly and may be less effective than treatment in the community. ${ }^{28}{ }^{29}$ Furthermore, there had been concerns that hospitalisation could be associated with both nosocomial and community spread of 
Table 5 Regression model predicting poor outcome of four psychosocial wellbeing sub-domains

\begin{tabular}{|c|c|c|c|}
\hline $\begin{array}{l}\text { Social } \\
\text { disconnectiont } \\
\text { Adjusted OR }(95 \% \mathrm{Cl})\end{array}$ & $\begin{array}{l}\text { Separation from } \\
\text { family } \\
\text { Adjusted OR }(95 \% \mathrm{Cl})\end{array}$ & $\begin{array}{l}\text { Fear of hospitals and } \\
\text { drugs } \S \\
\text { Adjusted OR } \\
(95 \% \mathrm{Cl})\end{array}$ & $\begin{array}{l}\text { Loss of social } \\
\text { responsibilities } 1 \\
\text { Adjusted OR } \\
(95 \% \mathrm{Cl})\end{array}$ \\
\hline
\end{tabular}

\begin{tabular}{|c|c|c|}
\hline \multicolumn{3}{|l|}{ Sex } \\
\hline Male & & 1.00 \\
\hline Female & & $0.08^{*}(0.08$ to 1.19$)$ \\
\hline No formal & 1.00 & \\
\hline Primary & $8.65^{\star}$ (0.93 to 15.09$)$ & \\
\hline
\end{tabular}

Post-secondary

Current employment status

$\begin{array}{lccl}\text { Unemployed } & 1.00 & 1.00 & 1.00 \\ \text { Employed } & 15.28^{* *}(1.51 \text { to } 30.94) & 13.42^{* *}(1.14 \text { to } 18.06) & 6.4^{* *}(1.18 \text { to } 34.54)\end{array}$

Person providing for children

$\begin{array}{ll}\text { Myself } & 1.00 \\ \text { My spouse } & 0.251(0.01 \text { to } 3.17) \\ \text { Others } & 6.04^{\star *}(2.51 \text { to } 9.14)\end{array}$

Number of TB treatments in the past

\begin{tabular}{|c|c|c|c|c|}
\hline$\leq 3$ & 1.00 & & & \\
\hline$>3$ & $0.06^{\star *}(0.00$ to 0.73$)$ & & & \\
\hline \multicolumn{5}{|c|}{ Number of years on TB treatment } \\
\hline $3-4$ & $5.18(0.23$ to 10.4$)$ & $3.18(0.37$ to 6.90$)$ & $1.81(0.20$ to 16.19$)$ & \\
\hline $5-10$ & $14.05^{\star \star}(2.59$ to 20.2$)$ & $7.76^{\star \star}(2.20$ to 15.14$)$ & $4.20(0.52$ to 33.50$)$ & \\
\hline \multicolumn{5}{|c|}{ Current duration of admission } \\
\hline $1-2$ & 1.00 & 1.00 & 1.00 & 1.00 \\
\hline $3-4$ & $6.40^{\star \star}(1.66$ to 13.54$)$ & $7.50(0.59$ to 14.13$)$ & $2.06^{\star *}(1.65$ to 5.2$)$ & $8.21^{* *}(1.57$ to 17.30$)$ \\
\hline $5-6$ & $7.04(0.49$ to 12.43$)$ & 0.706 (0.05 to 3.73$)$ & $2.46(0.37$ to 6.03$)$ & $1.68(1.35$ to 9.98$)$ \\
\hline $7-8$ & $10.14^{\star}(0.94$ to 36.79$)$ & $8.41^{\star \star}(1.48$ to 14.32$)$ & $5.06^{\star \star}$ (2.40 to 10.02$)$ & $5.60^{*}(0.66$ to 14.30$)$ \\
\hline
\end{tabular}

*Significant at $p<0.10 ;{ }^{* *}$ significant at $p<0.05$.

†Model $\chi^{2}=34.606, p=0.000$, Negelkerk $R^{2}=0.635$.

†Model $\chi^{2}=24.786, p=0.000$, Negelkerk $R^{2}=0.546$.

$\S$ Model $\chi^{2}=23.98, p=0.004$, Negelkerk $R^{2}=0.440$.

IModel $\chi^{2}=7.452, p=0.115$, Negelkerk $R^{2}=0.150$.

Variables included in each logit model were sex, age, religion, marital status, education, current employment status, children, children in school, person providing for children, family visits, number of TB treatments in the past, number of years on TB treatment, and current duration of admission.

TB, tuberculosis.

DR-TB, especially if there are waiting lists to enter the hospital. ${ }^{29}$ To this extent, it is being increasingly recommended that long-term hospitalisation should be considered only and exclusively when all other measures to ensure adherence to treatment have been systematically exhausted. As an alternative, community-based outpatient treatment with measures put in place to ensure adherence is being increasingly advocated. ${ }^{18}$

In our study setting, we had ethical concerns which included a small but significant waiting list. In addition, while we strive to maintain a high standard of observance of human rights, there are no strong patient advocacy groups in Nigeria to provide the necessary checks and balances. The power relation between the patients (who are often of low socioeconomic status) and the attending health professionals is usually unbalanced such that patients are often subservient to the health workers. In such settings, it is easy for a patient's rights to be inadvertently violated. The observation that all the inpatients 
approached for this study agreed to participate with few questions asked supports this point.

Our main motivations for the continued use of the hospitalisation approach include non-availability of a social support network to facilitate adherence in ambulatory treatment, and the fact that we have recorded an excellent adherence rate $(100 \%)$ among inpatients. ${ }^{3}$ This was despite the prohibitive cost of hospital admission, a growing waiting list, and other ethical concerns. In the present study, the finding of a high level of other psychosocial concerns such as real or perceived stigma, hospital anxiety, loss of income, and isolation from family and friends among respondents adds to the growing list of concerns with hospital-based management of MDR-TB. This calls for a further scrutiny of the hospitalisation policy and a continued search for less burdensome alternatives.

The main challenges of community-based treatment, which could be an alternative form of treatment strategy for MDR-TB, have always been poor drug adherence and the active management of drug side-effects. ${ }^{30}$ Given the ethical issues earlier highlighted about hospitalbased care, the real paradigm shift is to strike a balance by carefully combining hospital- and community-based approaches. $\mathrm{WHO}^{31}$ recommends that when other factors such as trained response personnel for adverse drug reactions and social support systems to enhance drug adherence are present, hospitalisation should be used only for very sick patients. It is our considered opinion that it is possible and feasible to divert some of the funds currently being used to provide hospital-based treatment to create an adverse drug reaction response team for ambulatory MDR-TB management units as well as to provide drug adherence incentives to outpatients.

The current support staff in the inpatient service such as public health nurses can be trained as first responders to adverse drug reactions, and a doctor attached to each ambulatory unit can then act as a second responder. Each ambulatory unit can be registered to a maximum number of patients who will have unfettered mobile phone access to the unit in case of distress. In addition, adherence can be ensured by identifying and training family treatment supporters on drug adherence monitoring techniques while providing incentives such as a monthly food basket, economic assistance for transport, and house rent for the patient and their supporters. When drug adherence is made conditional, this approach will serve as a form of conditional transfer among economically vulnerable patients, which are the bulk of patients in our facilities. This approach has improved adherence and overall success in MDR-TB in other treatment settings in Africa. ${ }^{32}$

\section{CONCLUSION}

In conclusion, we have argued that the problems associated with hospital-based treatment for MDR-TB have gone beyond high costs and long waiting lists to include several psychosocial problems and concerns which relate directly to the prolonged hospitalisation. If strategies are put in place to manage adverse drug reactions and incentives are put in place to enhance drug adherence, community-based treatment will reduce the waiting list, reduce the psychosocial burden of treatment on the patients, and may in the long run be cost-effective. These conclusions are, however, very theoretical as they stand, and the insights provided here need to be integrated into further cost-effectiveness studies. Such studies should factor in the cost of incentives for outpatient treatment of MDR-TB and the cost estimate of the psychosocial burden of prolonged hospitalisation.

\section{Author affiliations}

${ }^{1}$ HIV/AIDS, STIS \& TB (HAST) Programme, Human Sciences Research Council (HSRC), South Africa

${ }^{2}$ Discipline of Public Health Medicine, College of Health Science, Howard College Campus, University of KwaZulu-Natal, Durban, South Africa

${ }^{3}$ Regional Psychosocial Support Initiative (REPSSI), Randburg, South Africa

${ }^{4}$ HIV/AIDs Treatment Unit, Centre for the Aids Programme of Research in

South Africa (CAPRISA)

${ }^{5}$ Respiratory Unit, Department of Medicine, College of Medicine, University

College Hospital, Ibadan, Nigeria

${ }^{6}$ Nigeria Center for Disease Control, Abuja, Nigeria

${ }^{7}$ Stop TB Partnership, Geneva, Switzerland

${ }^{8}$ Department of Behavioral Medicine, Lagos State University College of Medicine Ikeja Lagos, Ikeja, Lagos, Nigeria

${ }^{9}$ Department of Community Medicine and Primary Healthcare, Bingham

University, Nasarawa, Nigeria

${ }^{10}$ Damien Foundation Belgium, Nigeria

${ }^{11}$ Programme Management Unit, KNCV Tuberculosis Foundation, Nigeria

\section{Handling editor Seye Abimbola}

Acknowledgements We acknowledge the efforts of the research assistants and the staff of the MDR-TB treatment centres.

Contributors Conceived and designed the experiments: 00, BAU, KEO; performed the experiments: 00, KEO, BAU, EEU; analysed the data: 00, KEO, BAU, EEU, MG, O0, DL, OA, LL, OMI, OE, JMT; contributed reagents/ materials/analysis tools: 00, KEO, BAU, EEU, MG, 00, DL, OA, LL, OMI, OE, JMT, CSC, CAl; wrote and approved the final version of the manuscript: 00, KEO, BAU, EEU, MG, O0, DL, OA, LL, OMI, OE, JMT, CSC, CAI.

Funding This study was supported by the Center for Community Health Care, Research and Development, Nigeria (CCHARD) http://www.cchrad.org.

Competing interests None declared.

Patient consent Obtained.

Ethics approval Oyo state, Ministry of Health, Ethics Committee.

Provenance and peer review Not commissioned; externally peer reviewed.

Data sharing statement No additional data are available.

Open Access This is an Open Access article distributed in accordance with the Creative Commons Attribution Non Commercial (CC BY-NC 4.0) license, which permits others to distribute, remix, adapt, build upon this work noncommercially, and license their derivative works on different terms, provided the original work is properly cited and the use is non-commercial. See: http:// creativecommons.org/licenses/by-nc/4.0/

\section{REFERENCES}

1. Herchline TE, Cunha BA, Chavis PS, et al. Tuberculosis. Medscape Reference, WebMD, Updated: March 2012. 
2. National Institute of Health. Tuberculosis. Medscape Reference, WebMD. 2009. http://www.niaid.nih.gov/topics/tuberculosis/ understanding/whatistb/pages/tbdefinitions.aspx (accessed 21 Jul 2015).

3. Oladimeji $O$, Isaakidis $P$, Obasanya OJ, et al. Intensive-phase treatment outcomes among hospitalized multidrug-resistant tuberculosis patients: results from a nationwide cohort in Nigeria. PLoS One 2014;9:e94393.

4. World Health Organization. Multidrug and extensively drug-resistant TB (M/XDR.TB): 2010 global report on surveillance and response. Geneva, Switzerland: World Health Organization; WHO/HTM/TB/ 2010.3.

5. Omole MK, Ebitigha O. A ten-year study of pharmacotherapeutic approach to tuberculosis at a tertiary hospital in south west Nigeria. Int J Pharm Biomed Res 2011;2:153-7.

6. Ofukwu RA, Oboegbulem SI, Akwuobu CA. Zoonotic Mycobacterium species in fresh cow milk and fresh skimmed unpasteurized market milk (nono) in Makurdi, Nigeria: implications for public health. J Anim Plant Sci 2008;12:21-5.

7. Lawson L, Zhang J, Gomgnimbou MK, et al. A molecular epidemiological and genetic diversity study of tuberculosis in Ibadan, Nnewi and Abuja, Nigeria. PLoS One 2012;7:e38409.

8. World Health Organization. Global tuberculosis control: epidemiology, strategy, financing. Geneva: WHO, 2009. http:// whqlibdoc.who.int/publications/2009/9789241598866_eng.pdf

9. Federal Ministry of Health, Nigeria (FMOH). National drug resistance TB prevalence survey report. August 2012.

10. World Health Organization (WHO). Multidrug and extensively drug resistant TB (M/XDR-TB): global report. 2013.

11. Ahuja SD, Ashkin D, Avendano M, et al. Multidrug resistant pulmonary tuberculosis treatment regimens and patient outcomes: an individual patient data meta-analysis of 9,153 patients. PLoS Med 2012;9:e1001300.

12. Marra CA, Marra F, Cox VC. Factors influencing quality of life in patients with active tuberculosis. Health Qual Life Outcomes 2004;2:58.

13. Uplekar M, Raviglione M. Hospital or home? Scripting a high point in the history of TB care and control. WHO South-East. Asia J Public Health 2012;1:220-3.

14. Cohen SD, Sharma T, Acquaviva K, et al. Social support and chronic kidney disease: an update. Adv Chronic Kidney Dis 2007; 14:335-44

15. Hon KL, Pong NH, Poon TCW, et al. Quality of life and psychosocial issues are important outcome measures in eczema treatment. J Dermatolog Treat 2015;26:83-9.

16. Zhong $\mathrm{N}$, Yuan $\mathrm{Y}, \mathrm{Chen} \mathrm{H}$, et al. Effects of a randomized comprehensive psychosocial intervention based on cognitive behavioral therapy theory and motivational interviewing techniques for community rehabilitation of patients with opioid use disorders in Shanghai, China. J Addict Med 2015;9:322-30.

17. Directorate of Tuberculosis Control. Management of drug-resistant tuberculosis in South Africa: Policy guidelines. Pretoria: South African Department of Health; 2007.
18. World Health Organization. Guidelines for the programmatic management of drug-resistant tuberculosis. Geneva: WHO, 2011. (WHO/HTM/TB/2011.6).

19. Long $\mathrm{NH}$, Johansson $\mathrm{E}$, Diwan VK, et al. Fear and social isolation as consequences of tuberculosis in VietNam: a gender analysis. Health Policy 2001;58:69-81.

20. Macq J, Solis A, Martinez G. Assessing the stigma of tuberculosis. Psychol Health Med 2006;11:346-52.

21. Ushie BA, Jegede AS. The paradox of family support: concerns of HIV and TB co-infected patients about involving family and friends in their treatment. AIDS Patient Care STDS 2012;26:647-53.

22. Komiti $A$, Judd $F$, Jackson $H$. The influence of stigma and attitudes on seeking help from a GP for mental health problems: a rural context. Soc Psychiatry Psychiatr Epidemiol 2006;41:738-45

23. Lieber E, Li L, Wu Z, et al. HIV/STD stigmatization fears as health-seeking barriers in China. AIDS Behav 2006;10:463-71.

24. Baral SC, Aryal Y, Bhattrai Y, et al. The importance of providing counselling and financial support to patients receiving treatment for multi-drug resistant TB: mixed method qualitative and pilot intervention studies. BMC Public Health 2014;14:46. http://www. biomedcentral.com/1471-2458/14/46 (accessed 31 Jul 2015).

25. Bender A, llene $\mathrm{H}$, Sepali $\mathrm{G}$, et al. Exploring the link between tuberculosis and mental health among immigrants. Can J Nurs Res 2012;44:56-75.

26. Gebremariam MK, Bjune GA, Frich JC. Barriers and facilitators of adherence to TB treatment in patients on concomitant TB and HIV treatment: a qualitative study. BMC Public Health 2010;10:651.

27. Asuquo AE, Pokam BT, Adindu A, et al. Health-related quality of life (HRQoL) of tuberculosis (TB) patients in Akwa lbom State, Nigeria. J Tuberc Res 2014;2:199.

28. Fitzpatrick C, Floyd K. A systematic review of the cost and cost effectiveness of treatment for multidrug-resistant tuberculosis. Pharmacoeconomics 2012;30:63-80.

29. Bassili A, Fitzpatrick C, Qadeer E, et al. A systematic review of the effectiveness of hospital- and ambulatory-based management of multidrug-resistant tuberculosis. Am J Trop Med Hyg 2013;89:271-80.

30. Heller T, Lessells RJ, Wallrauch CG, et al. Community-based treatment for multidrug-resistant tuberculosis in rural KwaZulu-Natal, South Africa. Int J Tuberc Lung Dis 2010;14:420-6.

31. World Health Organization. Management of MDR-TB: a field guide. A companion document to guidelines for the programmatic management of drug-resistant. Geneva: WHO, 2009, tuberculosis $\mathrm{WHO} / \mathrm{HTM} / \mathrm{TB} / 2008.402 \mathrm{a}$

32. Meressa D, Hurtado RM, Andrews JR, et al. Achieving high treatment success for multidrug-resistant TB in Africa: initiation and scale-up of MDR TB care in Ethiopia--an observational cohort study. Thorax 2015;70:1181-8. 